\title{
Definitional skills and preferred definition types according to age, gender, educational level and career orientation
}

Dourou, Chrisoula $\$

Democritus University of Thrace, Greece (chdouro@helit.duth.gr)

Gavriilidou, Zoe

Democritus University of Thrace, Greece (zoegab@otenet.gr)

Markos, Angelos

Democritus University of Thrace, Greece (amarkos@eled.duth.gr)

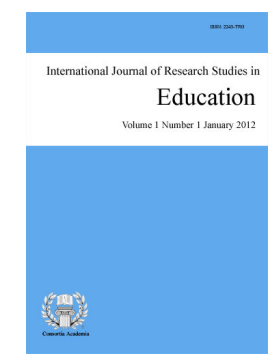

ISSN: 2243-7703 Online ISSN: 2243-7711

OPEN ACCESS

\section{Abstract}

The purpose of this study was to empirically investigate the definitional skills and the preferred definition type of school-age children, university students and adults and to examine the effect of variables such as, age (preschool, elementary, secondary and university), gender, adult educational level and career orientation (humanities vs science). The sample consisted of 322 individuals, who were asked to define 16 words orally. Definitions were scored on a five-point scale along a continuum that reflects the developmental path of the definitions. The results indicated that definitions tend to conform to the conventional rules of the Aristotelian format so that, with increasing age, females outperform males, science students outperform students in humanities, and adults with university education outperform adults without university education. The implications of these findings for lexicography and education are also discussed. This study expands the extant literature on definitional skill development.

Keywords: word definition; definitional skills; language development; definition types; content and form of definitions 


\section{Definitional skills and preferred definition types according to age, gender, educational level and career orientation}

\section{Introduction}

"Definitions are a kind of judgement that either establishes a new piece of knowledge-as in the case of a new scientific discovery (e.g., radio waves)—or renders already existing and shared information explicit (e.g., the definition of 'apple' or 'beauty')" (Benelli, Belacchi, Gini, \& Lucangeli, 2006, p. 72). On the other hand, providing word definitions is a metalinguistic task, in other words a reflection on the meaning of words, and it is also a communicative task, where the speaker's intention is to achieve relevance (Watson, 1995). All definitions include formal and content components in the sense that they combine informative contents with appropriate forms (Benelli et al., 2006). Combining forms with contents is not an easy task and previous research has shown that this ability is influenced by formal instruction. Actually, children learn gradually to combine content and form to produce definitions.

The manner in which children define words has been extensively investigated (Werner \& Kaplan, 1963; Storck \& Looft, 1973; Anglin, 1977; Benelli, Arcuri, \& Marchesini, 1988; Nippold, Hegel, Sohlberg, \& Schwarz, 1999, Gavriilidou, 2015). As Marinellie and Johnson (2004, p. 217) claim, "This is not surprising, given that definitional skill has been closely related to cognitive and linguistic development, literacy, and academic achievement in school-age children". While at school, children become capable of reflecting on their own linguistic productions and assessing their ability to do so. As a result, at school they learn how to produce 'formal' definitions based on either a specific type of class inclusion (e.g., chair - it is a furniture) or a general one (chair - it is something where we sit).

Previous research on definitional skills has mainly focused on (1) differences in definitional performance according to age (Watson, 1985; Miller \& Gildea, 1987; McKeown, 1993; Fischer, 1994; Nippold, 1995; Nist \& Olejnik, 1995; Scott \& Nagy, 1997), educational level (Watson, 1985; Snow 1990, Gutierrez-Glellen \& DeCurtis, 1999; Benelli et al., 2006) or grammatical category of the stimulus word (Johnson \& Anglin, 1995; Skwarchuk \& Anglin, 1997; Marinellie \& Johnson, 2003, Gavriilidou, 2015), (2) the metalinguistic nature of definition (Watson, 1995; Benelli et al., 2006) (3) the properties of content and form of definitions and how these evolve according to the age.

This study builds upon previous research on definitional skills, seeking to empirically investigate the preferred definition types according to age, gender, educational level and career orientation.

\section{Research background}

\subsection{Types of word definitions}

Descriptive features, functional terms, examples, or classificatory terms may be included in words' definitions (Guttierrez-Clellen \& DeCurtis, 1999). According to Makau (1990), formal definitions (e.g., a bicycle is a means of transport including a steering wheel, a saddle and two wheels) are differentiated from other types of definitions. Formal definitions include the form " $\mathrm{X}$ is a $\mathrm{Y}$ that $\mathrm{Z}$, where $\mathrm{Y}$ is the superordinate term and $\mathrm{Z}$ a differentiating characteristic of the targeted word X. On the other hand, informal definitions do not include a superordinate term.

Functional definitions are a kind of informal definitions, which build on the characteristics that define the concept that differentiate it from the others and the term is defined relative to a specific event (e.g., courage is riding on the roller coaster). Moreover, a functional definition is intended to convey the meaning we give to a 
Definitional skills and preferred definition types according to age, gender, education and career orientation

concept, based on our experiences and observations. Children prefer definitions by function or purpose, especially when they refer to either the function of an object or to the purpose of an event (e.g. run - to lose weight) (Gavriilidou, 2015). Children, also, use definitions by self-reference, referred to themselves, their opinion and personal experience (e.g. box - I have one in which I keep my toys) and descriptive definitions, referred to the attributes of the definiendum, (shape, color, dimension etc.).

Other informal definitions may include an example (e.g., for example, cricket is a popular sport in England). Definitions by example are always used by children when they exemplified different types of the definiendum showing awareness of the aim of the message as directed to a receiver (e.g. mushrooms - there are poisonous and good mushrooms) (Gutierrez-Clellen \& DeCurtis, 1999; Caramelli, Borghi, \& Setti, 2006).

The case of fuzzy or non-definitions encountered is Tautology, when the child repeats the definiendum (e.g. apple - is an apple or friendship - to have a friend). According to Dourou (2018, 2019), the types of definition are divided into the Lexicographic definition, the Aristotelian definition and the Fuzzy definition. The Lexicographic definition includes Definition by Synonym, Definition by Example, Descriptive Definition, Functional Definition, and Morphological Definition. Finally, based on their extension, definitions are divided into formal and extended ones (Table 1).

\section{Table 1}

Typology of definitions

\begin{tabular}{|c|c|c|c|c|}
\hline \multirow{7}{*}{$\begin{array}{l}\text { Types of } \\
\text { definition }\end{array}$} & \multirow{5}{*}{ Lexicographic definition } & Definition by synonym & Extended definition & \multirow{7}{*}{ Extension } \\
\hline & & Descriptive definition & Extended definition & \\
\hline & & Functional definition & Extended definition & \\
\hline & & Definition by example & Extended definition & \\
\hline & & Morphological definition & Formal definition & \\
\hline & Aristotelian definition & & Formal definition & \\
\hline & Fuzzy definition & & Extended definition & \\
\hline
\end{tabular}

Adults use different types of word definitions than children in the sense that children's definitions are often deficient in comparison with definitions provided by adults. Investigations have found that, from preschool age to adolescence and adulthood, definitions develop from those definitions that are functional and concrete to those that are more abstract and conceptual. Nippold (1995) claimed that children demonstrate significant qualitative changes in their definitional skills during the school years. These developmental changes could be attributed either to changes in the organization of the conceptual lexicon (Skwarchuk \& Anglin, 1997) or to a greater metalinguistic awareness in the sense that one can use two words, a superordinate term and basic level term, for a referent (McGhee-Bidlack, 1991). However, Watson (1995) reported that children often know the superordinate terms but fail to use them in definitions. This may happen because young children fail to manipulate both the meaning of a word and the form of definitions (Gavriilidou, 2015).

\subsection{Nature of definitions: Content and form}

Each definition is a combination of an informative content and a formal structure. Formal structures correspond -more or less- to the definition types described in the previous section. Learning to combine form and content, usually takes place in school, at the beginning without any explicit or direct instruction, but indirectly through teachers' speech which stands as a model in classroom, but later through systematic teaching.

According to Marinellie and Johnson (2004, pp. 228-229), "typically developing school-age children are competent in choosing content: They do not merely rely on low-level responses such as examples, associations, or locations. Rather, the content expressed in noun definitions (definitions of things) and verb definitions (definitions of actions) is diverse ". In addition, although it is possible that children may be more experienced in defining nouns than verbs, "perhaps verb knowledge is salient and memorable because verbs or actions, more so that nouns or objects, are connected to events" (Marinellie \& Johnson, 2004, p. 229). Moreover, nouns are more 
frequently defined with the use of superordinate terms or a combination in the style of definitions than verbs.

In relation to form, Marinellie and Johnson (2004) argue that there is a typical formal structure for verb and noun definitions. The most frequent structure for nouns, is the Aristotelian form and for the infinitive structure, to (verb) or (verb phrase) with a modifying phrase or clause. According to Markowitz and Franz (1988), these similarities in noun and verb form correspond to child's development. Finally, Johnson and Anglin (1995) found that it was easier for children to provide conventional syntactic form for nouns than verbs. While practice in school may certainly be helpful, Johnson and Anglin suggested that nouns more often lead to activation of a categorical or superordinate term.

\subsection{Age}

Research on word definitions has shown that age is one of the most important factors affecting the definition ability. These studies, comparing different age groups, indicate that there are both quantitative and qualitative changes in children's word definitions as they grow older (Storck \& Looft, 1973; Litowitz, 1977; Wehren, De Lisi, \& Arnold, 1981; Benelli et al., 1988; Snow, 1990; Johnson \& Anglin, 1995; Nippold, 1995; Watson, 1995).

Children attending school are often required to manipulate word meanings and use their lexical knowledge to provide word definitions for words they read or hear in the classroom (Gavriilidou, 2015). As children progress through the school-age years, the language demands placed on them increase to ones that require an awareness of and analytical approach to language (van Kleeck, 1994). One such skill is the ability to understand a word meaning, as presented in a typical definition, and use information from the definition to gain insight about the semantic and syntactic properties of an unfamiliar word.

Starting from the age of five (5), however, research has shown that the definitions focus primarily on function and description (e.g., "box: put toys in / e.g., cat: do mum") (Gavriilidou, 2015). As many studies showed (Storck \& Looft, 1973; Benelli et al., 1988) children, at this age, produce definitions based on perceptual or functional information and without formal terms (Watson, 1995). Once they reach their school years (approximately 5 years old), children begin to use the nonspecialized category of something (e.g., the cat is doing something 'naughty') (Litowitz, 1977).

Some studies (Feifel \& Lorge, 1950; Werner \& Kaplan, 1963; Storck \& Looft, 1973; Swartz \& Hall, 1972; Anglin, 1977) consider the age of seven (7) to be a milestone in the development of word definition abilities because they begin to produce more precise definitions, to use more specific categorical terms in conjunction with functional and descriptive features of the defining concept (e.g., the cat is a mammoth and has hair (Anglin, 1977; Litowitz, 1977; Benelli et al., 1988; Snow, Cancino, Gonzalez, \& Shriberg, 1989; Snow, 1990; Watson, 1995).

As age increases, differences emerge in the ability to define words based on their semantic characteristics. In the Nippold et al. (1999) study, individuals aged twelve (12), fifteen (15), eighteen (18) and twenty-three (23) years were asked to define substantially low-frequency abstract terms (e.g., weight, humility) presented in random order. Responses were scored on the use of the term surname. The results of the study showed that the answers improved with age. The researchers conclude that the ability to define abstract nouns has a prolonged development that ends in early adulthood. McGhee-Bidlack (1991) reports that, in subjects of age eighteen (18), these abstract nouns are essentially defined mainly by the surname (e.g., 'a flower is a plant that has multicoloured petals'), whereas abstracts are essentially defined in terms of their characteristics, with the subordinate terms often omitted. Of course, age interrelates with educational level (see below) and probably other factors in a rather complex way. During childhood it is difficult to differentiate the effects of educational level from mere age effects caused by maturational changes, as the two factors undoubtedly co-vary (Benelli et al., 2006). 


\subsection{Gender}

A plethora of research on the existence and nature of differences between men and women has been carried out in the last few decades. One of the interesting areas within the remit of sociolinguistics has been the amount of variation on the part of men and women when they use language. This popularity stems, in part, from the fact that language is an inherently social phenomenon and can provide insight into how men and women approach their social worlds. An increasing consensus of findings suggests that men, relative to women, are more likely to use language more for the instrumental purpose of conveying information; women tend to use verbal interaction for social purposes with verbal communication serving as an end in itself (Herring, 1993; Brownlow, Rosamon, \& Parker, 2003; Colley, Todd, Bland, Holmes, Khanom, \& Pike, 2004).

Many studies (McMillan, Clifton, McGrath, \& Gale, 1977; Biber, Conrad, \& Reppen 1998; Mulac, Bradac, \& Gibbons, 2001; Mehl \& Pennebaker, 2003) have examined gender variations through the actual words men and women use. They found that women use more intensive adverbs, (e.g. more connectors such as but and more modal auxiliary verbs such as could). In contrast, it has been pointed out that men use longer words, more articles, more references to location and swear more (Gleser, Gottschalk, \& John, 1959; Mulac \& Lundell, 1986; Mehl \& Pennebaker, 2003).

However, on the exception of Gavriilidou (2015) who studied the effect of gender on the definition of word stimuli belonging to different grammatical categories (nouns, verbs, adjectives), no other study focusing on definitional skills has looked at that parameter, even though previous research indicated differences such as the number and the type of the actual words men and women use or the length of sentences they produce. These two parameters may play an important role to speakers' definitional performance and affect the content, put other way the information contained in the definition or its form, in other words the internal organization of lexical elements and grammatical patterns used in definition formulation.

\subsection{Educational level}

Educational level is a powerful factor in the ability to define as well as in the type of word definition provided. Several studies have noted a very significant difference between adults with a high educational level and adults with a low educational level. This indicates that formal education is, also, an important factor affecting to the definition ability. More specifically, research conducted by Luria (1976) with Uzbek adults, who were farmers by profession, found that adults who did not study defined essentials based on their perceptual or functional characteristics, while some failed to define words at all. Rather, they 'framed' the definition into a 'short story' in which the definite concept was involved. The level of definition of adult words with a low educational level was equivalent to that of a 6-year-old child.

Walker (2001), also, studied the relationship between educational attainment and definition skills in low-income rural adults (from 24 to 70 years) and high-income urban adults (20 to 64 years). Walker asked both groups of adults to define words that belong to the grammatical category of the noun. Its results showed that $80 \%$ of adults in urban settings included hypersonic terms in their definitions, while in the rural population, this was true for $36 \%$. Regarding the form of their responses, the ratio of definitions to 'formal' form (Partly Aristotelian/Aristotelian) was $69 \%$ for urban adults and only $13 \%$ for rural adults.

Regarding the type of definition chosen, the study conducted by Benelli et al. (2006) showed better performance in highly educated adults (HE: Highly Educated) than in low-educated adults (LE: Low Educated). The results showed that only $8 \%$ of the adults with low educational attainment were metalinguistic (i.e., definite meaning + surname + distinctive features), while the percentage of post-linguistic definitions for adults with a high educational attainment was more than $30 \%$. The authors conclude that formal definitions are associated with literacy, as overall low-educated adults used fewer Aristotelian ('post-linguistic') definitions than educated adults. 


\subsection{Career orientation}

There is -to our knowledge- no previous research relevant to definitional skills that investigates the direct effect of career orientation on definitional ability. Furthermore, previous literature on the topic is sparse regarding the effect of that factor to other aspects of linguistic or metalinguistic development. Politzer (1983) reports that major was a significant factor in some aspects of Foreign Language Learning, contrasting Engineers with Business/Social Studies/Education students. Ehrman and Oxford (1989) found a strong effect of career choice on language learning strategies. They connected this factor with an underlying parameter of integrative (socially-based) or instrumental motivation which they claimed can be inferred in career orientation results. Finally, in Oxford and Nyikos (1989) it was shown that university major had a statistically significant influence on choice of second language learning strategies particularly in favor of humanities, social science and education majors and to a lesser degree to majors in computers, science or mathematics.

Career orientation could play an important role in the definitional performance of adults, since it may reflect different language use motivational goals and different instruction. Students in some majors (for instance Health Sciences-Medicine) are faced daily with definitions as a part of their formal instruction so they are interested in providing correct definitions to succeed to their exams and also do their jobs well in future (instrumental motivation), while students in other majors may have mixed (integrative or instrumental) relationship to their production of definitions.

Career orientation may also reflect socioeconomic status in the sense that socioeconomic status impacts educational opportunities (Hauser \& Warren, 1997; Eshelman, 2013). For instance, recent research has shown that the majority of medical students come from the upper two quintiles of family income (Jolly, 2008).

\subsection{Aims and hypotheses}

The general purpose of the present study was to investigate definitional skills and preferred definition types and how these differentiate according to various variables. The first aim was to investigate the definitional types in content and form preferred by the sample in total and, also, to examine the preferred definition types per age/educational level group, gender, university student career orientation and adult educational level. Based on previous literature (Johnson \& Anglin, 1995; Skwarchuk \& Anglin, 1997; Marinellie \& Johnson, 2003; Gavriilidou, 2015), we expected our sample to provide mid-level responses in content (Relation, Class non-specific, Class specific and Synonym) and in form (Phrase, Clause or Simple Sentence, Transitional form). We also expected that the types of word definitions (in content and form) provided by our sample would reflect the developmental path of the definitions and that educated adults and humanity students would provide Aristotelian or partially Aristotelian definitions in content and form.

The second aim was to study the effect of age on the performance of definitions (content and form) as individuals mature, from kindergarten through university. Specifically, and consistently with the literature on the development of definitional skills (Storck \& Looft, 1973; Litowitz, 1977; Wehren et al., 1981; Watson, 1985; Benelli et al., 1988; Snow, 1990; Johnson \& Anglin, 1995; Nippold, 1995), we expected that University students would outperform preschoolers, elementary and secondary school pupils.

The third aim was to analyse the effect of gender in the definitional ability (content and form) of the sample. Taking into consideration previous literature on the development of definitional skills we expected that female students would outperform male students in the definition of content and form (Huttenlocher, Haight, Bryk, Seltzer, \& Lyons, 1991).

The fourth aim was to examine the effect of educational level on the definition abilities (content and form) of adults included in our sample. Based on the literature investigating the metalinguistic components implied in definitional tasks (Wehren et al., 1981; McGhee-Bidlack, 1991), we expected that adults having received university education would outperform adults with lower educational level. 
Definitional skills and preferred definition types according to age, gender, education and career orientation

Finally our fifth aim was to shed light on the effect of students' career orientation on the content and form of definitions. In this context, we predicted that students of Humanities would perform better than students of Medical Sciences, because the former group of students, as future teachers, get more practice with providing definitions as part of their training and are expected make better use of language (both in syntactic and grammatical level) than the second.

\section{Methodology}

The study sample comprised 322 individuals, 140 males (43\%) and 182 females (57\%) of different age groups, from preschoolers to adults recruited through random sampling procedures. Table 2 presents the sample characteristics by age and gender.

Table 2

Participant characteristics across gender, ageleducational level, career orientation and university education

\begin{tabular}{lccc}
\hline \multicolumn{1}{c}{ Groups } & \multicolumn{2}{c}{ Gender } & \multirow{2}{*}{ Total } \\
\cline { 2 - 4 } & Male & Female & 33 \\
\hline Preschoolers (4-5 years old) & 16 & 17 & 36 \\
Lower Elementary (6-8 years old) & 21 & 15 & 35 \\
Upper Elementary (9-11 years old) & 16 & 19 & 35 \\
Junior High students (13-15 years old) & 17 & 18 & 50 \\
Senior High students (15-17 years old) & 23 & 27 & 83 \\
University students (19-24 years old) & 24 & 59 & 51 \\
$\quad$ in Humanities & 9 & 42 & 32 \\
$\quad$ in Medical Science & 15 & 17 & 50 \\
Adults (above 32 years old) & 23 & 27 & 25 \\
$\quad$ with university education & 10 & 15 & 12 \\
$\quad$ without university education & 13 & 182 & 322 \\
\hline Total & & & 25 \\
\hline
\end{tabular}

\subsection{Stimuli and procedures}

To ensure a valid and reliable measurement, the research protocol of Marinellie and Johnson (2002) as adapted in Gavriilidou (2015) was adopted. The data collection tool included sixteen (16) words, of which eight (8) were nouns, four (4) verbs and four (4) adjectives. Of the sixteen (16) words, ten (10) were identified according to their frequency through the Textbooks of the Modern Greek Language of Elementary School, Junior and Senior High School and the remaining were included from Gavriilidou's (2015) research. In order to check words' frequency, the textbooks were transformed into text files (txt) and they were introduced in the AntConc 3.5.0 program, in order to create word frequency lists.

The sixteen (16) words that were chosen a) from the school textbooks were erotisi 'question', taksiði 'journey', iKovasilema 'sunrise', makrozoia 'longevity', tiropita 'cheese pie', maçeropiruno 'cutlery', aspromavros

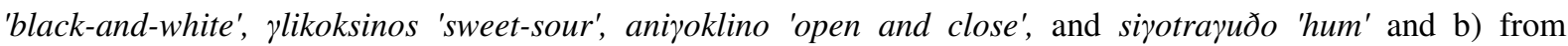
Gavriilidou's (2015) survey were milo 'apple', poðilato 'bicycle', eksipnos 'intelligent', astios 'funny', diavazo 'read', and xorevo 'dance'.

The questionnaire was administered orally by the first author of this paper to each participant, without the presence of other individuals during this process. It was deemed necessary to orally provide the instrument since the preschoolers included in the sample have not yet developed writing ability. Furthermore, oral administration minimized the risk of copying a definition through the internet or from a dictionary (electronic or printed).

The eight (8) nouns were interspersed with the four (4) verbs and four (4) adjectives in random order, and each participant was randomly assigned to an order. For nouns, the investigator asked: 'What is an X?' The 
article 'an' (or 'a') gives a strong indication to the child that he or she is defining a word from the grammatical class of 'noun' (Katz, Baker, \& Macnamara, 1974; Gelman \& Taylor, 1984). The use of a natural prompt for nouns would maximize the chance that children would interpret common words with multiple meanings, such as nouns. For each verb, the investigator asked the child: 'What does X mean?' The use of this natural prompt maximized the chances that the child would interpret these words as verbs. The data collection period lasted two months (October-December 2018). The study was approved by the Research Board of the Department of Greek of Democritus University of Thrace. Because children are involved in the research, we obtained written consent from their parents or legal guardians. All data were collected, kept and processed according to European and National General Data Protection Regulations.

\subsection{Scoring of data: Content}

The scoring methodology of Marinellie and Johnson (2002) was adopted for the needs of the present study. Content scoring is displayed in Table 3. Definitions were scored on a five-point scale along a continuum, consistent with a developmental progression suggested in previous literature. The highest possible noun content score for any participant was 80 points (16 words per participant, with a maximum of 5 points per word). The total number of definitions from the 322 participants was 5152 definitions ( $322 \times 16)$.

\section{Table 3}

Scoring scheme used for the content categories

\begin{tabular}{|c|c|c|}
\hline Content category & Example & Score \\
\hline Error & milo [apple : ice-cream] & 0 \\
\hline Function & tiropita [cheese pie: you eat it] & 1 \\
\hline Description & milo [apple: red and round] & 1 \\
\hline Present state & erotisi [question: what you are doing now] & 1 \\
\hline Example & $\begin{array}{l}\text { aniyoklino [open and close: for example, open and close the } \\
\text { door] }\end{array}$ & 1 \\
\hline Association /Result /Action & diavazo [read: history] & 1 \\
\hline Tautology & $\gamma$ likoksinos [sweet-sour: sweet and sour] & 1 \\
\hline Relation-Self-reference & eksipnos [intelligent: that's me] & 2 \\
\hline Class non-specific & poðilato [bicycle: a thing] & 2 \\
\hline Class specific & milo [apple: fruit] & 3 \\
\hline Synonym & eksipnos [intelligent: clever] & 3 \\
\hline Combination I & milo [apple: a thing that is red and round] & 4 \\
\hline Combination II & $\begin{array}{l}\text { poðilato [bicycle: means of transport with a steering wheel, } \\
\text { saddle and pedal] }\end{array}$ & 5 \\
\hline Lexicographic definition & diavazo [read: look at the words and understand their meaning] & 5 \\
\hline Aristotelian definition & erotisi [question: a clause that asks for answers] & 5 \\
\hline
\end{tabular}

Low-level responses were function, description, present state, example, association, and tautology. Mid-level responses were relation, class non-specific, class specific, and synonym. High-level responses included Combination I and II, lexicographic definition and Aristotelian definition.

\subsection{Scoring of data: Form}

Form scoring for words is displayed in Table 4. Definitions were scored on a five-point scale along a continuum, consistent with a developmental progression suggested by the literature on definition. This scoring scheme was used in a study of the definitional skill of school-age children with specific language impairment (Marinellie \& Johnson, 2002). Form categories included: Nonverbal; Single Word or Article + Word; Phrase, Clause, or Simple Sentence; Transitional; Partial Aristotelian; and Aristotelian. The highest possible form score for any participant was 80 points ( 16 words per participant, with a maximum of 5 points per word). 
Definitional skills and preferred definition types according to age, gender, education and career orientation

\section{Table 4}

Scoring scheme used for the form categories

\begin{tabular}{|c|c|c|}
\hline Form Category & $\begin{array}{c}\text { Example } \\
\end{array}$ & Score \\
\hline Nonverbal & $\begin{array}{l}\text { Participant demonstrates use of object or points to } \\
\text { object }\end{array}$ & 0 \\
\hline Single Word or Article + Word & iKovasilema [sunrise: evening] & 1 \\
\hline Phrase, Clause or Simple Sentence & milo [apple: we eat it] & 2 \\
\hline $\begin{array}{l}\text { Transitional form (use of "something" or } \\
\text { "thing" plus modifying clause) }\end{array}$ & erotisi [question: something that wants to answer] & 3 \\
\hline Partial Aristotelian form & milo [apple: a fruit] & 4 \\
\hline Aristotelian form & $\begin{array}{l}\text { poðilato [bicycle: means of transport with a steering } \\
\text { wheel, saddle, pedal and without motor] }\end{array}$ & 5 \\
\hline
\end{tabular}

\subsection{Reliability}

Content - Inter-rater reliability of content coding was evaluated for all responses given by 64 subjects. This refers to $20 \%$ of the data (1024 definitions). Identically coded responses were considered an agreement. The two raters were the principal investigator (first author) and a PhD student of the Department of Greek Philology of Democritus University of Thrace. The investigator's grade was hidden from the PhD student. The percentage of agreement was calculated by dividing the number of responses coded identically by the total number of coded responses (1024 definitions). For the content of the responses, 908 common responses were recorded indicating an inter-rater agreement of $88.6 \%$.

Form - Inter-rater reliability of form coding was evaluated for all responses in the same way as content coding. For the form of the responses, 952 common responses were recorded indicating an inter-rater agreement of $92.9 \%$.

\section{Results}

\subsection{Frequency of definition type (Content)}

The descriptive statistics (frequencies) of the data showed that the most common type of content definition is Association/Effect/Action (15.1\%). Combination II (13.9\%) and Tautology (12.2\%) are, also, included among the highest preferences of all age groups $(n=322)$. Class specific definitions were provided by the $11.1 \%$ of the sample, followed by Combination I (10.5\%) and Incorrect Answers (7.8\%). Finally, definitions by Example were provided only by $3.2 \%$ of the sample, while $2.2 \%$ produced Descriptive Definitions, $0.6 \%$ Relation/Self-Reference and $0.1 \%$ Present State.

More specifically, preschoolers seem to provide erroneous definitions when asked to define words. A large percentage of them tend to define words with Association/result/action followed by the categories of Tautology (especially for compound words) and Functional definition. The majority of Lower and Upper Elementary students use the categories Tautology and Association/result/action when they define words. More rarely, they define words using Lexicographic or Aristotelian definitions. The most frequent category for Junior High students, University students and Adults with university education is Combination II (use of Class-Specific or Synonym and at least one specifying attribute such as Function, Concrete, etc.). Finally, the Senior High students prefer to define words with Association/result/action while in less use are the categories Present State and Relation/Self-reference.

Among the category of University Students, those in Humanities define more frequently words with Combination I (any combination of Function, Concrete, Association, Relation, or Class-Nonspecific), in contrast 
Dourou, C., Gavriilidou, Z., \& Markos, A.

to University students in Medical Science who produce definitions belonging to the categories Combination II and Synonym. Adults on the other hand, prefer to provide definitions of the Association / result / action type. When we examine the two groups of Adults separately, Adults with university education produce definitions of the category Combination II, while Adults without university education associate the definition of words with a result or an action. For the uneducated Adults, the lowest rate of responses is concentrated on Lexicographic and Aristotelian definitions.

\section{Table 5}

Frequency of definition types in content by all samples

\begin{tabular}{|c|c|c|c|c|c|c|c|c|c|c|c|c|c|c|c|c|}
\hline Age groups & 莺 & 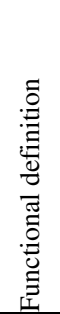 & 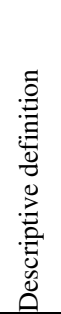 & 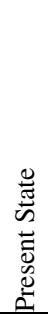 & 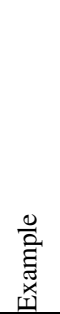 & 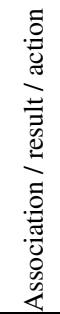 & 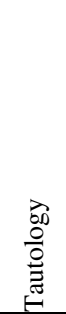 & 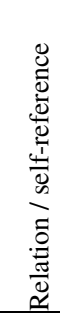 & 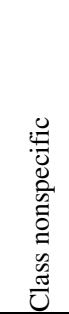 & 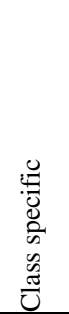 & 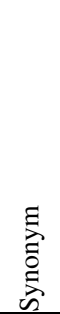 & 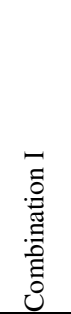 & 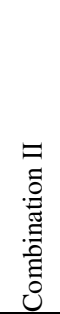 & 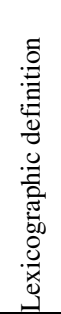 & 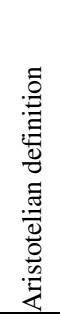 & $\stackrel{\bar{\pi}}{0}$ \\
\hline Preschoolers & 145 & 44 & 30 & 0 & 40 & 91 & 73 & 10 & 15 & 37 & 10 & 21 & 6 & 2 & 4 & 528 \\
\hline $\begin{array}{l}\text { Lower } \\
\text { Elementary }\end{array}$ & 68 & 54 & 26 & 0 & 31 & 109 & 126 & 3 & 36 & 46 & 8 & 36 & 32 & 1 & 0 & 576 \\
\hline $\begin{array}{l}\text { Upper } \\
\text { Elementary }\end{array}$ & 22 & 47 & 20 & 3 & 26 & 86 & 104 & 4 & 17 & 52 & 9 & 69 & 83 & 6 & 12 & 560 \\
\hline $\begin{array}{l}\text { Junior High } \\
\text { students }\end{array}$ & 24 & 6 & 7 & 1 & 22 & 38 & 97 & 3 & 23 & 68 & 41 & 52 & 109 & 20 & 49 & 560 \\
\hline $\begin{array}{l}\text { Senior High } \\
\text { students }\end{array}$ & 77 & 10 & 19 & 3 & 12 & 145 & 77 & 4 & 43 & 93 & 44 & 93 & 106 & 22 & 52 & 800 \\
\hline $\begin{array}{l}\text { University } \\
\text { students }\end{array}$ & 26 & 6 & 5 & 0 & 23 & 105 & 98 & 1 & 70 & 176 & 170 & 189 & 289 & 78 & 92 & 1328 \\
\hline Humanities & 26 & 6 & 5 & 0 & 16 & 84 & 77 & 1 & 67 & 116 & 91 & 147 & 124 & 13 & 43 & 816 \\
\hline $\begin{array}{l}\text { Medical } \\
\text { Science }\end{array}$ & 0 & 0 & 0 & 0 & 7 & 21 & 21 & 0 & 3 & 60 & 79 & 42 & 165 & 65 & 49 & 512 \\
\hline $\begin{array}{l}\text { Adults (above } \\
32 \text { years old) }\end{array}$ & 40 & 28 & 9 & 0 & 16 & 209 & 54 & 7 & 39 & 102 & 84 & 83 & 92 & 17 & 20 & 800 \\
\hline $\begin{array}{l}\text { with university } \\
\text { education }\end{array}$ & 6 & 5 & 3 & 0 & 1 & 73 & 30 & 2 & 13 & 54 & 47 & 56 & 77 & 15 & 18 & 400 \\
\hline $\begin{array}{l}\text { without } \\
\text { university } \\
\text { education }\end{array}$ & 34 & 23 & 6 & 0 & 15 & 136 & 24 & 5 & 26 & 48 & 37 & 27 & 15 & 2 & 2 & 400 \\
\hline Total & 403 & 195 & 116 & 7 & 170 & 783 & 629 & 32 & 243 & 574 & 366 & 543 & 717 & 146 & 228 & 5152 \\
\hline$\%$ & 7.8 & 3.7 & 2.2 & 0.1 & 3.2 & 15.1 & 12.2 & 0.6 & 4.7 & 11.1 & 7.1 & 10.5 & 13.9 & 2.8 & 4.4 & 100 \\
\hline
\end{tabular}

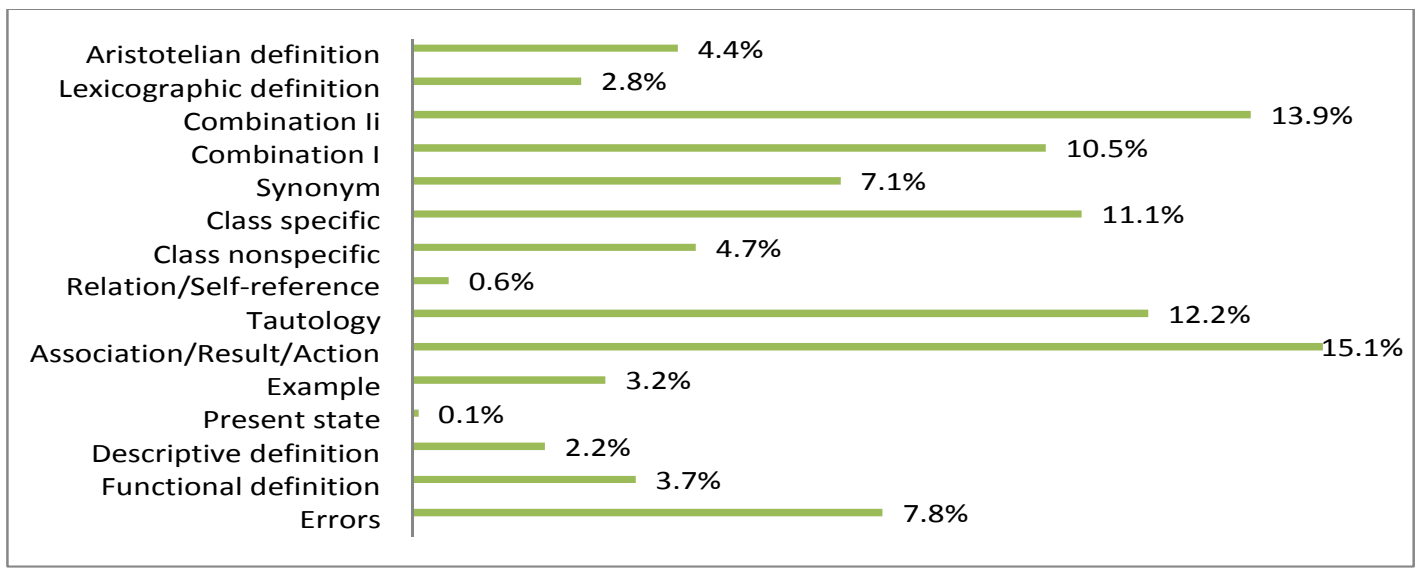

Figure 1. Frequency of definition types in content by all samples. 


\subsection{Frequency of definition types (Form)}

The descriptive statistics (frequencies) suggested that the most common type of definition in form is the Phrase/Simple Clause (34.6\%), followed by the Partial Aristotelian definition (32.6\%). The categories Transitional Form (12.4\%) and One Word or Article + Word (10.7\%) are placed in the mid-preferences of the participants in this research. The Aristotelian form is the least preferred type. Finally, only $1.8 \%$ of the sample provided nonverbal answers to word definitions.

The larger percentage of preschoolers and Lower / Upper Elementary students tend to prefer Phrase / Simple Clause (e.g. blouse: "you wear" climb: "climb a tree") for their definitions. But as we can see in the Table 14 this is inversely proportional with increasing age. For Junior and Senior High students, the responses are more focused on Partial Aristotelian Form (e.g. cat: "a kind of animal" walk: to move along) and Phrase / Simple Clause. Additionally, the categories with the lower rates among Junior and Senior High students are the Nonverbal definitions and the responses with Single Word or Article + Word.

For University students (both Humanities and Medical Science) and Adults the most frequent category is Partial Aristotelian form. Adults with university education also use Single Word or Article and Word more often than Clauses and Simple sentences (Phrase, Clause, or Simple Sentence) in definitions. In addition, adults without university education use One Word or Article and Word and Simple sentences (Phrase, Clause, or Simple Sentence) substantially more often than Transitional Form (e.g. "something" or "thing" followed by a modifying clause) and Aristotelian Form (formal structure).

\section{Table 6}

Frequency of definition types in form by all samples

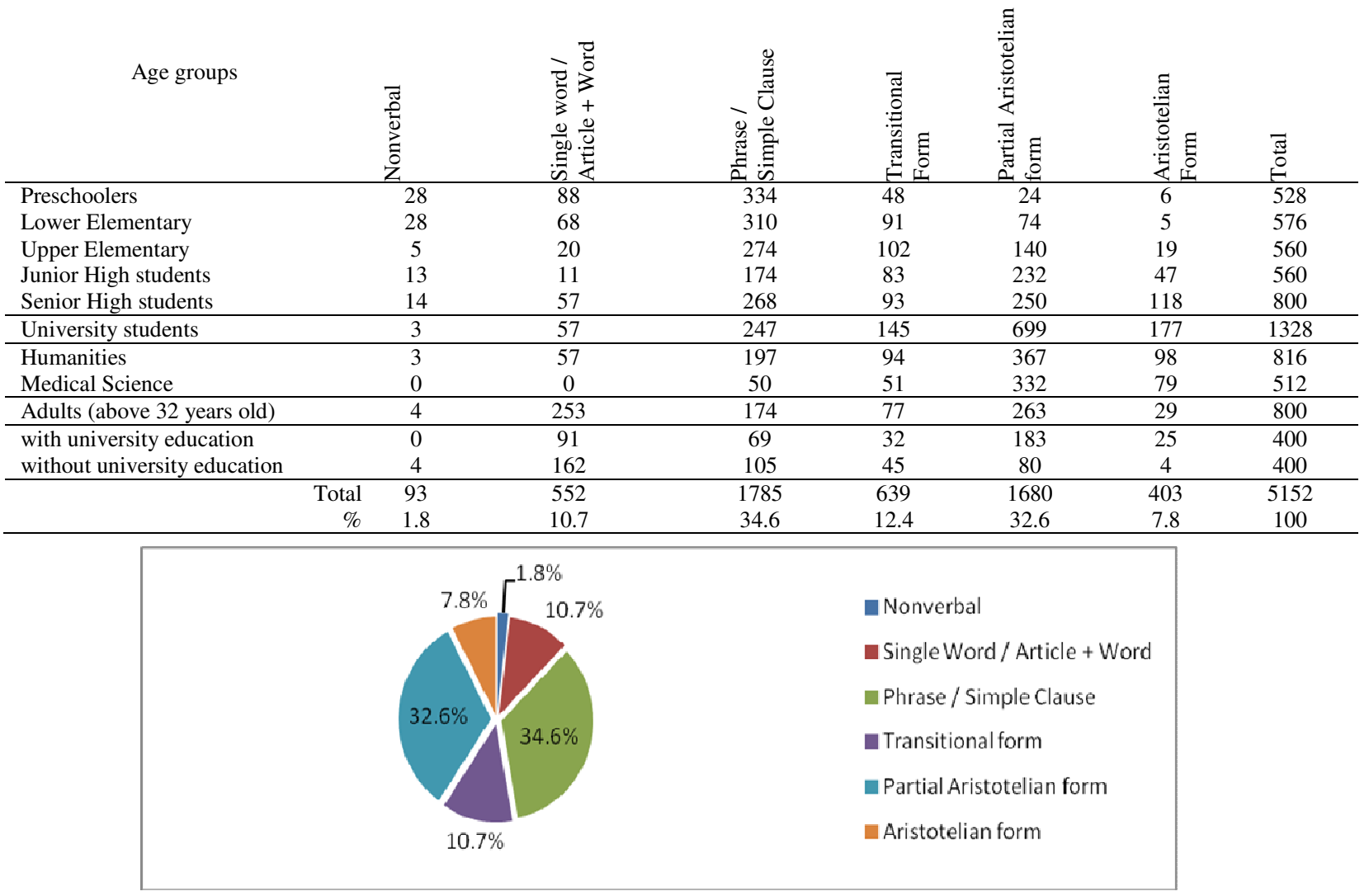

Figure 2. Frequency of definition types in form by all samples.

The results of two-way ANOVA showed that the main effects of age and gender on the overall score of 
Dourou, C., Gavriilidou, Z., \& Markos, A.

responses to the content of definitions were statistically significant $\left(F(5,272)=59.28, p<.001, \eta^{2}=.533\right.$ for age, Table 7 and $F(1,272)=8.00, p=.005, \eta^{2}=.030$ for gender, Table 8). In addition, the interaction between age and gender was not found statistically significant $(F(5,272)=2.161, p=0.059)$. With regard to age, post-hoc comparison tests indicated three distinct groups of participants with increasingly higher mean scores (Table 7, Scheffé criterion). The first group included Preschoolers and Lower Elementary School students. The means for this group were 22.06 points and 26.38 , respectively, with a maximum of 80 points. The second group included Upper Elementary, Junior High and Senior High School students. The means for this group were 39.05, 47.57 and 42.48 , respectively. Finally, the third group consisted of University students with a mean of 57.73. Moreover, females scored statistically significantly higher than males in all age groups ( 46.23 for females and 38.13 for males).

\section{Table 7}

Mean ages differences in the content of definitions

\begin{tabular}{lccc}
\hline \multicolumn{1}{c}{ Age/education group } & $n$ & Mean & SD \\
\hline Preschoolers & 33 & 22.06 & 9.18 \\
Lower elementary & 36 & 26.38 & 8.05 \\
Upper Elementary & 35 & 39.05 & 9.23 \\
Junior High students & 50 & 47.57 & 11.58 \\
Senior High students & 35 & 42.48 & 15.93 \\
University students & 83 & 57.73 & 12.84 \\
\hline
\end{tabular}

Table 8

Mean gender differences in the content of definitions

\begin{tabular}{|c|c|c|c|}
\hline Gender & $n$ & Mean & $S D$ \\
\hline Male & 117 & 38.13 & 17.32 \\
\hline Female & 155 & 46.23 & 16.68 \\
\hline Total & 272 & 42.74 & 17.39 \\
\hline
\end{tabular}

In line with the results obtained for the content of definitions, the main effects of age and gender on the overall score of responses to the form of definitions were found statistically significant $(F(5,272)=78.31, p$ $<.001, \eta^{2}=.601$ for age, Table 9 and $F(1,272)=7.72, p=0.006, \eta^{2}=.029$ for gender, Table 10). On the contrary, the interaction between age and gender was not statistically significant $(F(5,272)=2.077, p=.061)$. Scheffé's post hoc multiple comparisons revealed four distinct groups of participants with increasingly higher mean scores (Table 9). The first group included Preschoolers and Lower Elementary School students. The means for this group were 31.01 points for Preschoolers and 35.61 for Lower Elementary, respectively, with a maximum of 80 points. The second group consisted of Upper Elementary students with a mean of 43.68. The third group included Junior High students and Senior High students. The means for this group were 49.24 for Senior High students and 50.82 for Junior High students, respectively. Finally, the mean of the fourth group (University students) was 56.22. Moreover, females scored statistically significantly higher than males in all age/educational level groups (Table 10), with a mean of 49.03 for females and 43.97 for males.

\section{Table 9}

Mean age differences in the form of definitions

\begin{tabular}{|c|c|c|c|}
\hline Age/educational level group & $n$ & Mean & $S D$ \\
\hline Preschoolers & 33 & 31.01 & 5.33 \\
\hline Lower elementary & 36 & 35.61 & 5.45 \\
\hline Upper Elementary & 35 & 43.68 & 5.05 \\
\hline Junior High students & 50 & 50.82 & 7.35 \\
\hline Senior High students & 35 & 49.24 & 9.71 \\
\hline University students & 83 & 56.22 & 8.07 \\
\hline Total & 272 & 46.85 & 11.50 \\
\hline
\end{tabular}


Definitional skills and preferred definition types according to age, gender, education and career orientation

\section{Table 10}

Mean gender differences in the form of definitions

\begin{tabular}{|c|c|c|c|}
\hline Gender & $n$ & Mean & $S D$ \\
\hline Male & 117 & 43.97 & 11.45 \\
\hline Female & 155 & 49.03 & 11.09 \\
\hline Total & 272 & 46.85 & 11.50 \\
\hline
\end{tabular}

\subsection{The effect of university education on definitional ability}

As expected, Adults with university education scored statistically significantly higher than adults without a university degree on both content $(t(48)=4.726, p<.001, d=0.21$, Table 11$)$ and form of definitions $(t(48)=$ $6.008, p<.001, d=1.70$, Table 12).

\section{Table 11}

Mean differences on the content of definitions by adult education

\begin{tabular}{llcc}
\hline University education & $n$ & Mean & $S D$ \\
\hline Yes & 25 & 47.28 & 12.38 \\
No & 25 & 33.88 & 6.91 \\
\hline & 50 & 40.58 & 12.01 \\
\hline
\end{tabular}

Table 12

Mean differences on the form of definitions by adult education

\begin{tabular}{|c|c|c|c|}
\hline University education & $n$ & Mean & $S D$ \\
\hline Yes & 25 & 49.36 & 16.57 \\
\hline No & 25 & 27.00 & 8.47 \\
\hline Total & 50 & 38.18 & 17.23 \\
\hline
\end{tabular}

\subsection{The effect of career orientation on definitional ability}

Bootstrapped independent samples t-tests showed that the effect of career orientation on both content and form of definitions is statistically significant $(t(81)=6.518, p<.001$ for content and $t(81)=5.849, p<.001$ for form, respectively), indicating that Medical Science students scored statistically significantly higher than students of Humanities (Tables 13 and 14).

Table 13

Mean differences on the content of definitions by university student career orientation

\begin{tabular}{rlcc}
\hline \multicolumn{1}{c}{ Career orientation } & $n$ & Mean & $S D$ \\
\hline Students of Humanities & 42 & 51.80 & 12.08 \\
Students of Medical Science & 32 & 67.18 & 7.13 \\
\hline Total & 84 & 57.73 & 12.84 \\
\hline
\end{tabular}

\section{Table 14}

Mean differences on the content of definitions by university student career orientation

\begin{tabular}{rlll}
\hline \multicolumn{1}{c}{ Career orientation } & $n$ & Mean & $S D$ \\
\hline Students of Humanities & 51 & 52.76 & 7.67 \\
Students of Medical Science & 32 & 61.75 & 5.13 \\
\hline Total & 84 & 56.23 & 8.07 \\
\hline
\end{tabular}

\section{Discussion}

The purpose of the present study was to investigate definitional skills and preferred definition types and the 
effect of age, gender, career orientation and educational level on the performance of the sample.

\subsection{Preferred definition type by age, educational level and career orientation}

The first aim of this paper was to investigate the more frequent definitional types in content and form used by our sample. Our hypothesis was that participants would provide mid-level responses in content (Relation, Class non-specific, Class specific and Synonym) and in form (Phrase, Clause or Simple Sentence, Transitional form). Results from the present investigation do not confirm this hypothesis for content categories. The three most frequent types of content definition were the low-level category of Association/Result/Action followed by the high-level category of Combination II and the low-level category of Tautology. The least frequently used content categories were Present state (low-level category), Relation (medium-level category) and Descriptive definition (low-level category). This finding in line with previous literature (Marinellie \& Johnson, 2004; Johnson \& Anglin, 1995) and also reflects the stratification of our sample. Elementary and High school pupils and uneducated Adults mainly provided low-level categories, while University students and educated Adults provided high-level categories in their definitions. This result suggests interesting possibilities, allows for speculation and highlights the need to incorporate in elementary and secondary education explicit intervention programs integrated language teaching courses for acquainting pupils with dictionary use, make them aware of the characteristics of high-level definitions in content and create opportunities in classroom for training them in providing Aristotelian definitions thus raise their ability to make associations and search for relevant definitional elements within their mental lexicon. This presupposes that on the one hand children should develop their knowledge about the 'extralinguistic' world and on the other master the linguistic system.

As far as form of definitions is concerned, results confirmed our hypothesis, since the most frequent type is the medium-level category of Phrase/Simple Clause. The Aristotelian form of definition was the least frequently used type, while $1.8 \%$ of the sample provided nonverbal answers to word definitions. Once more this finding calls for the design of specific intervention programs during schooling for raising pupils' ability to provide Aristotelian definitions in form.

Our second hypothesis was that the types of word definitions (in content and form) provided by our sample would reflect the developmental path of the definitions and that educated adults and humanity students would provide Aristotelian or partially Aristotelian definitions in content and form. The descriptive analysis of the data (frequencies) confirms this hypothesis and yields a steady decrease in the lower-level categories of definitions in content and form and a steady increase of the quality of definitions in content and form as a function of age. Actually it was found that age development was proportional to the development of the definition ability.

Preschoolers provide incorrect definitions or definitions of Association/ Result/ Action and Tautology type. This result is in line with the research of Benelli et al., (1988) who found that the type of definition chosen by Preschoolers relates to relevant objects and they associate the meaning with another relevant event, person, thing or place.

It also agrees with findings reported in Litowitz (1977), who noted that the full clarification of formal definitions has not yet been mastered by young children during the first school years. Preschoolers use excessive generalization, based on some functional or perceptual similarity, trying to attribute the verbal meaning of a concept. A characteristic of this age in defining the meaning of a concept is its generality and its frequency of use. Children of this age also tend to give functional definitions (Anglin, 1977; Litowitz, 1977; Nelson, 1978; Norlin, 1981; Feifel \& Lorge, 1950; Wolman \& Barker, 1965) or use descriptive features as well as personal or hypothetical information in their definitions (Anglin, 1977; Litowitz, 1977).

Regarding to the form of definitions, preschoolers prefer the Phrase / Simple sentence. This finding is also supported by previous developmental studies (Benelli et al., 1988; Davidson, Kline, \& Snow, 1986; Johnson \& Anglin, 1995; Snow 1990), which showed that younger children - up to 5/6 years old - tend to give descriptions of the objects (using the HAS structure).

42 Consortia Academia Publishing (A partner of Network of Professional Researchers and Educators) 
Definitional skills and preferred definition types according to age, gender, education and career orientation

Tautology was the more frequent category used by Lower Elementary pupils followed by Association/Result/Action, while the most frequent type of form definition was Phrase / Simple sentence. Lower elementary pupils rely for content on low-level responses (Marinellie \& Johnson, 2004). Werner and Kaplan (1963) have noted that the age of seven (7) years is a milestone in the development of word definition and use strategies. As children grow older, the tendency exists to include in their definitions more than one feature of the concept they define. From the age of seven (7) years, they begin to produce definitions that are more precise, and they use more specific categorical terms combined with functional and descriptive traits. This happens because schooling seems to be the one of the most critical factors in the development of formal definitions (Snow, 1990; Snow et al., 1989), because children are exposed to formal language and definitions at school, whereas home environment provides more informal language (Snow, 1990).

Upper Elementary pupils choose Combination II for content, and Phrase/Simple clause definitions in form, which shows that pupils at this age start to use hyperonyms and their simple definitions are gradually becoming more formal. This is in line with the study of Caramelli, Borghi and Setti (2006) who found that children aged eleven (11) were able to define better words relating to a hyperonym, although their definitions are still based on tautology.

Junior High students, demonstrate a significant developmental maturation. They use Combination I definitions in content and Partially Aristotelian definitions in form. In fact, the ability of adolescents to define words is comparable to that of adults or university students as it was found in Nippold et al. (1999). According to Caramelli et al. (2006) thirteen (13) year old pupils, when define words, mainly refer to the causes, relationships, effects and actions of the concept and, also in form, their definitions seem to follow the Aristotelian model.

Senior High students, use low-level Association/ Result/ Action definitions in content and partially Aristotelian definitions in form. This is a quite surprising finding for content given that a developmental maturation in the ability of providing definitions was predicted. One possible explanation for this incongruence in results is that since Senior High students follow a demanding curriculum and teaching practices that privilege structure-oriented teaching for preparing them pass the exams for entering University, they focus only on school tasks and do not involve actively in any other extra-curricular activity such as the questionnaire that was administered to them in the frame of the present study. Furthermore, this preference to Association/Result/Action definitions is probably due to 'smart' or humorous answers given by pupils. They choose to define a word in any grammatical category to which it belongs by associating it with a person, a thing or a fact. However, their developmental evolution is reflected in the adoption of partially Aristotelian definitions in form (Dourou, 2019).

Definitions produced by university students in humanities are more detailed in terms of both content and form. They adopt Combination I definitions in content and partially Aristotelian definitions in form. This is the result of the training they receive during their studies since they are exposed to oral definitions during university lectures, but also to written definitions when reading scientific articles. In addition, practicing definition is a common activity in scientific discourse, since students produce and formulate definitions through writing texts, university papers, or during exams in various university courses. Also, the terminology used in scientific textbooks is a basic theoretical background for each individual field of science.

Finally, educated adults in our sample adopted Combination II definitions for content and partially Aristotelian definitions in form. This finding confirms previous research (Benelli et al., 2006) who found that that adults with a higher educational level performed better providing high-level definitions in content and form and showed that that the effects of different educational levels can be separated from the effects of increasing age. Their results showed that only $8 \%$ of the low-educated adult definitions were metalinguistic (i.e., definite meaning + hyperonyme + distinct characteristics), whereas the percentage of metalinguistic definitions for Adults with a high educational level was greater than $30 \%$. The authors concluded that formal definitions are linked to the educational level because low-educated Adults use fewer Aristotle definitions than Adults with university education. Additionally, Walker (2001) who studied the relationship between educational level and 
definitional skills, asked two groups of Adults to define words belonging to the grammatical category of noun. The results showed that $80 \%$ of adults from urban areas included hyperonym terms in their definitions. In contrast, only $36 \%$ of adults from rural areas included hyperonym terms in their definitions. Regarding the form of their answers, the definitions in 'typical' form (Partial Aristotle/Aristotelian) was 69\% for adults in urban areas and only 13\% for adults in rural areas. Additionally, many researchers (Spache, 1943; Terman, 1916; Wilson, 1975) have recognized the impact of sociological factors and education mainly on content of definitions.

\subsection{Age}

The second aim of this research was to study the effect of age on the performance of definitions in content and form. It was predicted that University students would outperform Preschoolers, Elementary and Secondary School pupils. The results confirmed this hypothesis. With respect to content, three distinct age groups were indicated by the results. The first group included Preschoolers and Lower Elementary pupils. The second group included Upper Elementary, Junior High and Senior High pupils. The third group consisted of University students who outperformed the other two age groups.

The first group has low performance, as indicated by mean scores, because - as Wehren et al. (1981) maintain - at this age, children have not acquired yet the relevant vocabulary, neither have built up an appropriate framework for the dissemination of information, or developed the ability to categorize.

The second group demonstrated better performance than Preschoolers but worse than that of University students. This is explained by the fact that at that age a new kind of vocabulary begins to develop, which is related to both spoken and written language and refers to concepts of new, specific cognitive domains. This vocabulary contains less-common words and names of abstract concepts and terminology (special and scientific vocabulary) (Anglin, 1977; Fiefel \& Lorge, 1950; Storck \& Looft, 1973; Swartz \& Hall, 1972). Futhermore, between the ages of 11 and 12, most children begin to think abstractly. According to Piaget, they have completed specific tasks and entered the formal operations stage. At this age, they have begun to use their language skills and literacy skills in all areas of school. The stage of formal operations will continue until adulthood and signifies a shift in children's thinking and speech. Additionally, during this age period, an increase in vocabulary occurs, words become fuller and more abstract, and metaphorical concepts and phrases are understood.

The highest score of responses was observed for university students, compared to all other age groups. The high performance of university students is connected to cognitive and metacognitive maturity but also to the extended use of academic vocabulary. According to Martin (1976, p. 92), academic vocabulary is defined as the high frequency words that appear in various texts of different disciplines and share the research, analysis and evaluation, i.e., the activities that characterize academic activity. The choice of the words in the academic vocabulary helps students not only to recognize familiar words but also to expand their knowledge of words that are not familiar to them.

With respect to form, and in contrast to content, four distinct groups were revealed. The first one, as happened for content, included Preschoolers and Lower Elementary pupils who had the worst performance of all other categories. The second group consisted of Upper Elementary pupils who had better performance in the definition task for form than Preschoolers but worse than all the other categories. The third group included Junior and Senior High School pupils who performed better than the first and second age group but worse than University Students. The fourth group included University students who outperformed all other age groups.

The questions that must be answered is why four distinct age groups are there for form and not three as found for content. Why Upper Elementary pupils constitute a separate age group? To answer these questions, we need to consider that correct form in definitions requires to provide a conventional syntactic form and to incorporate a specific superordinate term with a modifying phrase or clause. Pupils at this age barely start to use hyperonyms and, as they start to be syntactically aware, their simple definitions, are gradually becoming more formal but are still less elaborate than those of High School pupils. This is not the case with the content of their 
Definitional skills and preferred definition types according to age, gender, education and career orientation

definitions; content and form both improve with age, but they do not always develop together and in the same direction (Johnson \& Anglin, 1995; Marinellie, 2010; Litowitz, 1977; Wehren et al., 1981). As stated in Marinellie (2010, p. 181) "Until children learn to successfully coordinate content and form, they are generally more successful at providing precise word meaning (content) than in providing conventional syntax (form)".

\subsection{Gender}

The third aim of the paper was to investigate the effect of gender on the performance of the sample while providing definitions. A main effect of gender was found on the overall score of responses. We also hypothesized that girls would outperform boys. Our data confirmed this hypothesis; girls had better performance than boys in the definition task in all age groups. One possible explanation of that finding is that definitional ability could be part of the larger construct of linguistic skills. If this is true, then contemporary research shows that girls outnumber boys in most language skills assessments and demonstrate better verbal skills than boys (Huttenlocher et al., 1991). Furthermore, previous research indicated differences such as the number and the type of the actual words males and females use or the length of sentences they produce. These two parameters may affect the definitional ability of the two genders.

\subsection{Career orientation}

Our fourth aim was to investigate the effect of career orientation in content and form of definitions. It was found that career orientation had a statistically significant effect on both content and form of definitions. It was hypothesized that students of Humanities would outperform students in Medicine. This hypothesis was not confirmed by our data. The results showed that Medical Science students scored statistically significantly better than students of Humanities in content and form.

This result may be accounted by the fact that students are admitted to study in Medicine schools in Greece only after a demanding knowledge-based exam in which only $16 \%$ of them succeed, usually the more diligent of the candidates of all scientific fields. Those students have strong linguistic skills and ground knowledge of physics, chemistry and biology. Furthermore, during their studies they are systematically exposed -already from the first year- to the use of medical terminology. This fact acquaints them with the content and formal properties of definitions. This finding suggests that definitional skills are probably linked to an overall high linguistic competence and also practice with definitions during learning and that Medicine school curriculum may have a positive effect in students' ability to define words.

\subsection{Educational level}

The final aim of the study was to check the effect of educational level to the performance of Adults in the definition task. The present study has shown that the educational level has a significant effect on the content and form of the definitions. We predicted that Adults with university education would perform better than Adults without university education. Our hypothesis was confirmed by our results. Adults with university education of our sample outperformed adults without university education. Actually, Adults without university education performed worse than upper elementary pupils. Our finding is in line with previous research (Luria, 1976; Walker, 2001; Benelli et al., 2006) and seems to suggest that formal education plays an important role in the development of definition skills. It also suggests that the positive effect of schooling in definition abilities is short term and diminishes when no practice with definitions takes place during learning. The finding confirms previous research of Benelli et al (2006, p. 93) who claimed that "the effects of different educational levels can be separated from the effects of increasing age" in Adults.

\section{Restrictions and further investigation}

The results of the present study are consistent with many other studies that have shown that definitions tend to conform to the conventional rules of Aristotelian format, with increasing age and have highlighted the 
significant effect of variables such as gender, career orientation and educational level on definitional ability.

The findings of the study can improve the developmental assessment tools in speech pathology and intelligence testing. They can also be used in direct vocabulary teaching, which is necessary for students to acquire a basic vocabulary covering basic communication needs. Additionally, the word definition categories resulting from this research can be integrated into the techniques of learning meaningful words in the target language and can be included in textbooks of teaching Greek as a second foreign language (depending on age or other variables).

The findings of this study can also be exploited in the design of explicit and integrated in language course intervention programmes to improve the ability to define words, and c) the inclusion of specific categories of words in textbooks according to age or other variables. Therefore, one of the main goals of language teaching in the school environment, which is to enhance the lexical competence of the students, could be met. As a result, the development of vocabulary, definitions of words could be learned (Nagy, Anderson, \& Herman, 1987).

The extension and enrichment of vocabulary competence contributes not only to the effective realization of the students' communication intentions but also to the successful formulation of academic speech to respond to the needs of the school assessment. Consequently, lexical awareness is not only a basic component of the pupils' wider linguistic competence but is also a prerequisite for the appropriate recruitment, assimilation and consolidation of the knowledge offered in all school subjects. Finally, the findings of this study can also be used in lexicography to improve the definitions of words in the interpretations of the lemmas, thereby making dictionaries more useful. We are fully aware that our data require further theoretical documentation and empirical verification.

Repeating and confirming the present research (replication of research) taking into consideration new variables would ascertain the degree of reliability and validity and would permit to further generalizing the results. For instance, another important aspect to consider in future research is the parameter of bilingualism and its effect on definition skills of monolingual and multilingual speakers. The ability to define words of age groups residing in different areas, such as urban or semi-urban, could also be studied.

The present investigation included stimulus words that were all in the high-frequency range. In future studies, the incorporation of high-frequency as well as low-frequency words would be useful to investigate the effect of word frequency on definition. Such investigations should allow for greater insight into the development of this important skill as well as into the organization of the mental lexicon.

The results of this study highlight the factors that influence the oral definition ability. Future research could focus on studying the ability to define words at the written level because the production of oral and written language is an important aspect of a child's educational development; therefore, ongoing research clarifies the unique conceptual, linguistic and translation constraints for oral and written language.

Acknowledgment - «This research is co-financed by Greece and the European Union (European Social FundESF) through the Operational Program «Human Resources Development, Education and Lifelong Learning» in the context of the project "Strengthening Human Resources Research Potential via Doctorate Research" (MIS-5000432), implemented by the State Scholarships Foundation (IKY)». It was approved by the 149/15-12-2015 decision of the Research Board of the Department of Greek of Democritus University of Thrace.

\section{References}

Anglin, J. (1977). Word, object and conceptual development. New York: Norton.

Benelli, B., Arcuri, L., \& Marchesini, G. (1988). Cognitive and linguistic factors in the development of word definitions. Journal of Child Language, 15(3), 619-635. https://doi.org/10.1017/S0305000900012599

46 Consortia Academia Publishing (A partner of Network of Professional Researchers and Educators) 
Definitional skills and preferred definition types according to age, gender, education and career orientation

Benelli, B., Belacchi C., Gini, G., \& Lucangeli, D. (2006). To define means to say what you know about thing: The development of definitional skills as metalinguistic acquisition. Child Language, 33(1), 71-97. https://doi.org/10.1017/S0305000905007312

Biber, D., Conrad, S., \& Reppen, R. (1998). Corpus linguistics: Investigating language structure and use. Cambridge, England: Cambridge University Press. https://doi.org/10.1017/CBO9780511804489

Brownlow, S., Rosamon, J. A., \& Parker, J. A. (2003). Gender-linked linguistic behavior in television interviews. Sex Roles, 49, 121-132. https://doi.org/10.1023/A:1024404812972

Caramelli, N., Borghi, A. M., \& Setti, A. (2006). The identification of definition strategies in children of different ages. Linguistica Computazionale, 26, 155-178. https://doi.org/10.1400/59033

Colley, A., Todd, Z., Bland, M., Holmes, M., Khanom, M., \& Pike, H. (2004). Style and content in emails and letters to male and female friends. Journal of Language and Social Psychology, 23, 369-378. https://doi.org/10.1177\%2F0261927X04266812

Davidson, R. G., Kline, S. B. \& Snow, C. E. (1986). Definitions and definite noun phrases: indicators of children decontextualized language skills. Journal of Research in Childhood Education, 1, 37-48. https://doi.org/10.1080/02568548609594907

Dourou, C. (2018). The word definition ability of junior and senior high students. In the Proceedings of $39^{\text {th }}$ annual meeting department of linguistics, school of philology Aristotle University of Thessaloniki (pp. 395-413). Greece. [In Greek]

Dourou, C. (2019). The comparison of definition ability of different age groups [Doctoral dissertation]. Department of Greek Philology, Democritus University of Thrace. [In Greek]

Ehrman, M., \& Oxford, R. (1988). Effects of sex differences, career choice, and psychological type on adult language learning strategies. Modern Language Journal, 72(3), 253-265. https://doi.org/10.2307/327503

Eshelman, A. (2013). Socioeconomic status and social class as predictors of career adaptability and educational aspirations in high school students [Masteral thesis]. Southern Illinois University, Carbondale.

Feifel, H., \& Lorge, I. (1950). Qualitative differences in the vocabulary responses of children. Journal of Educational Psychology, 41(1), 1-18. https://doi.org/10.1037/h0058880

Fischer, U. (1994). Learning words from context and dictionaries: An experimental comparison. Applied Psycholinguistics, 15(4), 551-574. https://doi.org/10.1017/S0142716400006901

Gavriilidou, Z. (2015). The development of noun, verb and adjective definitional awareness in Greek preschoolers, Journal of Applied Linguistics, 30, 44-58.

Gelman, S., \& Taylor, M. (1984). How two-year old children interpret proper and common names for unfamiliar objects. Child Development, 55, 1535-1540. https://doi.org/10.2307/1130023

Gleser, G. C., Gottschalk, L. A., \& John, W. (1959). The relationship of sex and intelligence to choice of words: A normative study of verbal behavior. Journal of Clinical Psychology, 15(2), 183-191. https://doi.org/10.1002/1097-4679(195904)15:2<182::AID-JCLP2270150219>3.0.CO;2-7

Gutierrez-Clellen, V., \& DeCurtis, L. (1999). Word definitional skills in Spanish speaking children with language impairment. Communication Disorders Quarterly, 21(1), 23-31. https://doi.org/10.1177/152574019902100104

Hauser, R. M., \& Warren, J. R. (1997). Socioeconomic indexes for occupations: A review, update, and critique. Sociological Methodology, 27(1), 177-298. https://doi.org/10.1111/1467-9531.271028

Herring, S. C. (1993). Gender and democracy in computer-mediated communication. Electronic Journal of Communication, 3(2). Retrieved from http://www.cios.org/www/ejc/v3n293.htm

Huttenlocher, J., Haight, W., Bryk, A., Seltzer, M., \& Lyons, T. (1991). Early vocabulary growth: Relation to language input and gender. Developmental Psychology, 27(2), 236-248. https://doi.org/10.1037/0012-1649.27.2.236

Johnson, C. J., \& Anglin, J. M. (1995). Qualitative developments in the content and form of children's definitions. Journal of Speech and Hearing Research, 38(3), 612-629. https://doi.org/10.1044/jshr.3803.612

Jolly, P. (2008). Diversity of US medical students by parental income. AAMC Analysis in Brief, 8(1), 1-2. 
Retrieved from https://www.aamc.org/download/102338/data/aibvol8no1.pdf

Katz, N., Baker, E., \& Macnamara, J. (1974). What's in a name? A study of how children learn common and proper names. Child Development, 45 (2), 469-473. https://doi.org/10.2307/1127970

Litowitz, B. (1977). Learning to make definitions. Journal of Child Language, 4(2), 289-304. https://doi.org/10.1017/S0305000900001665

Luria, A. (1976). Cognitive development: Its cultural and social foundations. Cambridge: Harvard University Press.

Makau, J. M. (1990). Reasoning and communication: Thinking critically about arguments. Belmont, CA: Wadsworth.

Marinellie, S. (2010). Improving children's formal word definitions: A feasibility study. Child Language Teaching and Therapy, 26(1), 23-37. https://doi.org/10.1177/0265659009349970

Marinellie, S. A., \& Johnson C. (2004). Nouns and verbs: A comparison of definitional style. Journal of Psycholinguistic Research, 33(3), 217-235. https://doi.org/10.1023/B:JOPR.0000027963.80639.88

Marinellie, S. A., \& Johnson, C. (2003). Adjective definitions and the influence of word frequency. Journal of Speech, Language \& Hearing Research, 46(5), 1061-76. https://doi.org/10.1044/1092-4388(2003/084)

Marinellie, S. A., \& Johnson, C. J. (2002). Definitional skill in school-age children with specific language impairment. Journal of Communication Disorders, 35(3), 241-259. https://doi.org/10.1016/S0021-9924(02)00056-4

Markowitz, J., \& Franz, S. (1988). The development of defining style. International Journal of Lexicography, 1(3), 253-267. https://doi.org/10.1093/ijl/1.3.253

Martin, A. (1976). Teaching academic vocabulary to foreign graduate students. TESOL Quarterly, 10(1), 91-97. https://doi.org/10.2307/3585942

McGhee-Bidlack, B. (1991). The development of noun definitions: a metalinguistic analysis. Journal of Child Language, 18(2), 417-434. https://doi.org/10.1017/S0305000900011132

McKeown, M. (1993). Creating effective definitions for young word learners. Reading Research Quarterly, 28(1), 17-31. https://doi.org/10.2307/747814

McMillan, J. R., Clifton, A. K., McGrath, D., \& Gale, W. S. (1977).Women's language: Uncertainty or interpersonal sensitivity and emotionality? Sex Roles, 3, 545-559. https://doi.org/10.1007/BF00287838

Mehl, M. R., \& Pennebaker, J. W. (2003). The sounds of social life: A psychometric analysis of students' daily social environments and natural conversations. Journal of Personality \& Social Psychology, 84(4), 857-870. https://doi.org/10.1037/0022-3514.84.4.857

Miller, G., \& Gildea, P. (1987). How children learn words. Scientific American, 257(3), 94-99. https://doi.org/10.1038/scientificamerican0987-94

Mulac, A., \& Lundell, T. L. (1986). Linguistic contributors to the gender-linked language effect. Journal of Language and Social Psychology, 5(2), 81-101. https://doi.org/10.1177/0261927X8652001

Mulac, A., Bradac, J. J., \& Gibbons, P. (2001). Empirical support for the gender-as-culture hypothesis: An intercultural analysis of male/female language differences. Human Communication Research, 27(1), 121-152. https://doi.org/10.1111/j.1468-2958.2001.tb00778.x

Nagy, W., Anderson, R. C., \& Herman, P. (1987). Learning word meanings from context during normal reading. American Educational Research Journal, 24(2), 237-270. https://doi.org/10.3102/00028312024002237

Nelson, K. (1978). Semantic development and the development of semantic memory. In K. E. Nelson (ed.), Children's language (Vol. 1). New York: Gardner Press.

Nippold, M. A., Hegel, S., Sohlberg, M. M., \& Schwarz, I. (1999). Defining abstract entities: Development in preadolescents, adolescents, and young adults. Journal of Speech, Language, and Hearing Research, 42, 473-481. https://doi.org/10.1044/jslhr.4202.473

Nippold, M.A. (1995). School age children and adolescents: norms of word definitions. Language, Speech \& Hearing Services in Schools, 26(4), 320-325. https://doi.org/10.1044/0161-1461.2604.320

Nist, S., \& Olejnik, S. (1995). The role of context and dictionary definitions on varying levels of word knowledge. Reading Research Quarterly, 30(2), 172-193. https://doi.org/10.2307/748031

Norlin, P. F. (1981). The development of relational arcs in the lexical semantic memory structures of young

48 Consortia Academia Publishing (A partner of Network of Professional Researchers and Educators) 
Definitional skills and preferred definition types according to age, gender, education and career orientation

children. Journal of Child Language, 8(2), 385-402. https://doi.org/10.1017/S0305000900003251

Oxford, R., \& Nyikos, M. (1989). Variables affecting choice of language learning strategies: A synthesis of studies with implications for strategy training. System, 17(3), 235-247. https://doi.org/10.1111/j.1540-4781.1989.tb06367.x

Politzer, R. (1983). An exploratory study of self-reported language learning behaviors and their relation to achievement. Studies in Second Language Acquisition, 6(1), 54-65. https://doi.org/10.1017/S0272263100000292

Scott, J. A., \& Nagy, W. E. (1997). Understanding the definitions of unfamiliar verbs. Reading Research Quarterly, 32(2), 184-200. https://doi.org/10.1598/RRQ.32.2.4

Skwarchuk, S., \& Anglin, J. M. (1997). Expression of superordinates in children's word definitions. Journal of Educational Psychology, 89(2), 298-308. https://doi.org/10.1037/0022-0663.89.2.298

Snow, C. E. (1990). The development of definitional skill. Journal of Child Language, 17(3), 697-710. https://doi.org/10.1017/S0305000900010953

Snow, C. E., Cancino, H., Gonzalez, P., \& Shriberg, E. (1989). Giving formal definitions: An oral language correlate of school literacy. In D. Bloome (Ed.), Literacy in classrooms (pp. 233-249). Norwood, NJ: Ablex.

Spache, G. (1943). The vocabulary tests of the revised Stanford-Binet as independent measures of intelligence. Journal of Educational Research, 36(7), 512-516. https://doi.org/10.1080/00220671.1943.10881190

Storck, P. A., \& Looft, W. R. (1973). Qualitative analysis of vocabulary responses from persons aged six to sixty-six plus. Journal of Educational Psychology, 65(2), 192-197. https://doi.org/10.1037/h0034907

Swartz, K., \& Hall, A. (1972). Development of relational concepts and word definitions in children five through eleven. Child Development, 43(1), 239-244. https://doi.org/10.2307/1127887

Terman, L. (1916). The measurement of intelligence. Boston: Houghton-Mifflin. https://doi.org/10.1037/10014-000

van Kleeck, A. (1994). Metalinguistic development. In G. Wallach \& K. Butler (Eds.), Language learning disabilities in school-age children and adolescents: Some principles and applications (pp. 53-98). New York, NY: Macmillan.

Walker, S. (2001). Cognitive, linguistic, and social aspects of adults' noun definitions. Journal of Psycholinguistic Research, 30, 147-161. https://doi.org/10.1023/A:1010325811939

Watson, R. (1985). Towards a theory of definition. Journal of Child Language, 12(1), 181-197. https://doi.org/10.1017/S0305000900006309

Watson, R. (1995). Relevance and definition. Journal of Child Language, 22(1), 211-222. https://doi.org/10.1017/S0305000900009703

Wehren, A., De Lisi, R., \& Arnold, M. (1981). The development of noun definition. Journal of Child Language, 8(1), 165-175. https://doi.org/10.1017/S0305000900003081

Werner, H., \& Kaplan, B. (1963). Symbol formation. New York: Wiley.

Wilson, J. A. (1975). Development and social interaction in categories of word definition. British Journal of Educational Psychology, 45(3), 268-278. https://doi.org/10.1111/j.2044-8279.1975.tb02964.x

Wolman, R. \& Barker, E. (1965). A developmental study of word definitions. Journal of Genetic Psychology, 107, 159-166. https://doi.org/10.1080/00221325.1965.10532773 
Dourou, C., Gavriilidou, Z., \& Markos, A.

50 Consortia Academia Publishing (A partner of Network of Professional Researchers and Educators) 